\title{
MANSONELLA PERSTANS MICROFILARIAE IN PERIPHERAL BLOOD- A CASE REPORT FROM BIHAR
}

\author{
Namrata Kumari ${ }^{1}$, Babita $^{2}$, Shailesh Kumar 3 , Anima Xess ${ }^{4}$, Shivendra. K. Shahi ${ }^{5}$
}

${ }^{1}$ Additional Professor, Department of Microbiology, Indira Gandhi Institute of Medical Sciences, Patna.

${ }^{2}$ Assistant Professor, Department of Microbiology, Nalanda Medical College and Hospital, Patna.

${ }^{3}$ Additional Professor, Department of Microbiology, Indira Gandhi Institute of Medical Sciences, Patna.

${ }^{4}$ Professor, Department of Microbiology, Indira Gandhi Institute of Medical Sciences, Patna.

5 Professor and HOD, Department of Microbiology, Indira Gandhi Institute of Medical Sciences, Patna.

\section{ABSTRACT}

\section{BACKGROUND}

Mansonella infections have rarely been found in India. Here we found a case of Mansonella perstans infection in Patna, Bihar. Bunches of microfilariae were found in the Giemsa stained peripheral blood smears. Identification was done morphologically. A combination treatment with diethylcarbamazine (DEC) and mebendazole was given for one month. In follow-up visit after one month, he was relieved of the symptoms as well as microfilariae from peripheral blood. Survey must be done to know the prevalence and more about the parasite in Bihar.

\section{KEYWORDS}

Mansonella Perstans, Microfilariae, Bihar, India.

HOW TO CITE THIS ARTICLE: Kumari N, Babita, Kumar S, et al. Mansonella perstans microfilariae in peripheral blood- a case report from Bihar. J. Evolution Med. Dent. Sci. 2017;6(10):813-814, DOI: 10.14260/Jemds/2017/177

\section{BACKGROUND}

Mansonella perstans is a vector- borne human filarial nematode, transmitted by tiny blood- sucking flies called midges. ${ }^{1}$ It is widespread in many parts of sub-Saharan Africa, parts of central and south America and the Caribbean.1,2

Compared to infections with other filarial parasites, Mansonella infections are relatively mild. ${ }^{3}$ The overall disability among populations in regions where these filariae are endemic has been difficult to determine because of high rates of coinfection with other filariae and the non- specificity of M. perstans infections. ${ }^{3}$

Here we find a case of Mansonella perstans infection from Patna, Bihar; a state situated in northern part of India.

\section{CASE REPORT}

A fifty years old non-diabetic and non-smoker male from village area came to a private practitioner of the city with vague symptoms of mild cough, occasional wheeze, mild fever, headache and arthralgia, off and on for three months. The Giemsa stained slides of peripheral blood smears (thin and thick) were sent to the Microbiology lab, I.G.I.M.S. Patna (a tertiary care hospital) for comments and opinion.

Bunches of microfilariae were found in the slides (Fig. 1). Individual larva was recognized as that of Mansonella perstans by its characteristics of having blunt tails with their nuclei extending to the end of the tail and the absence of the sheath (Fig. 2 \& 3).

Routine laboratory investigations were within normal limits except mild increase in eosinophil percentage $(07 \%)$ in

Financial or Other, Competing Interest: None.

Submission 25-12-2016, Peer Review 08-01-2017,

Acceptance 25-01-2017, Published 02-02-2017.

Corresponding Author:

Dr. Namrata Kumari,

Additional Professor,

Department of Microbiology,

IGIMS, Sheikhpura-800014,

Patna, India.

E-mail: nrainrai@gmail.com

DOI: $10.14260 /$ jemds $/ 2017 / 177$

(c) $($ ) $९$ differential count of blood and mildly elevated serum $\operatorname{IgE}$ level ( $>450 \mathrm{IU} / \mathrm{ml}$, normal range, 0-380 IU/ml). Neither physical examination of the patient nor $x$-ray chest showed any abnormality or positive finding. There was no history of travelling to endemic area.

A combination treatment with diethylcarbamazine (DEC) and mebendazole was given for one month. In follow-up visit after one month, he was relieved of the symptoms as well as microfilariae from peripheral blood.

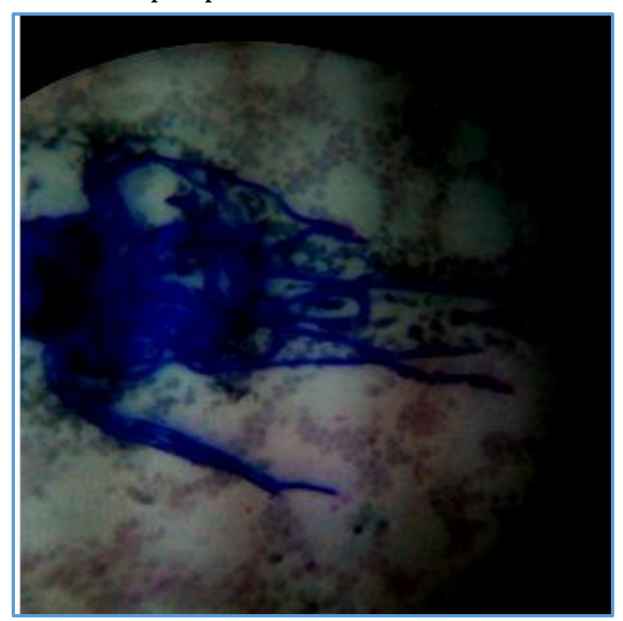

Figure 1. Microfilariae in bunch, under 10X, Giemsa staining

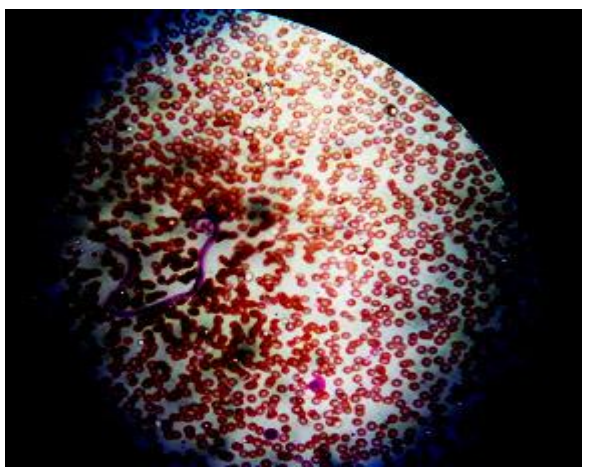

Figure 2. Microfilaria under 40X, Giemsa staining 


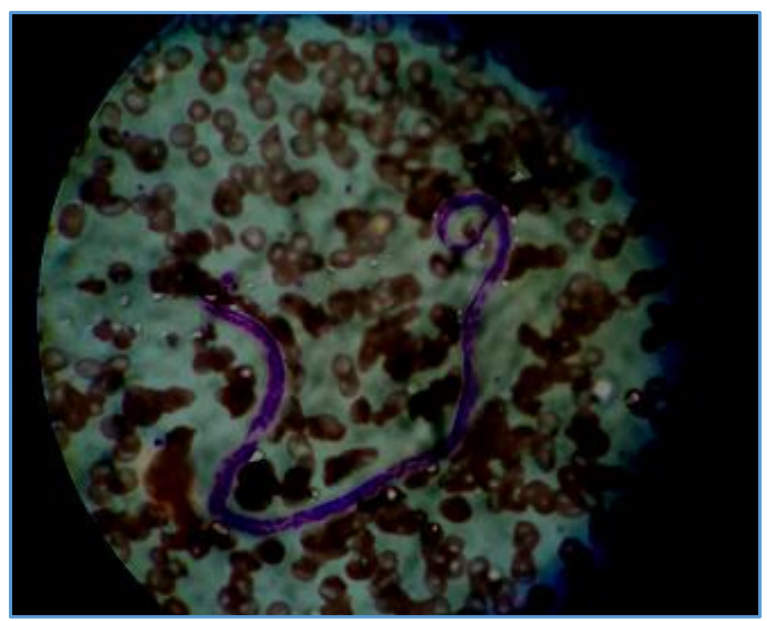

Figure 3. Microfilaria under 100X, Giemsa staining

\section{DISCUSSION}

Mansonellosis has rarely been found in India. ${ }^{4}$ To the best of our knowledge, no case has been reported at Bihar hospitals till now. However, few cases belonging to the area has been documented by the All India Institute of Medical Sciences (AIIMS), New Delhi.

Mansonella infection usually is present as co-infection with some other filarial worm or parasite or bacteria. ${ }^{3}$ Here it presented singly. Some other cases also, from India have been documented as single parasite (Mansonella perstans) infection. ${ }^{4}$

The characteristic of absence of sheath is found in M. ozzardi, M. streptocerca and Onchocerca volvulus also. Morphological differentiation between them is done on the basis of other characteristics. ${ }^{5}$

As this infection is poorly studied, treatment recommendations are based on limited data. Diethylcarbamazine in combination with mebendazole usually results in clearance of microfilaria of M. perstans in $37 \%$ at one month. Multiple treatments may be required for cure in individual patients, though there is not published evidence to guide a strategy. ${ }^{6}$

Prevention can be partially achieved through limiting contact with vectors by the use of repellents. The disease is generally asymptomatic or with mild symptoms; little has formally been done to control the disease.

\section{CONCLUSION}

Survey must be done to know the prevalence and more about the parasite in Bihar.

\section{REFERENCES}

[1] Simonsen PE, Onapa AW, Asio SM. Mansonella perstans filariasis in Africa. Acta Tropica 2011;120(Suppl 1):10920.

[2] Gideon. The Global Infections: disease and epidemiology network 2010. Mansonelliasis-perstans. http://web.gideononline.com

[3] Bregani ER, Rovellini A, Mbaidoum N, et al. Comparison of different anthelminthic drug regimens against mansonella perstans filariasis. Transactions of the Royal Society of Tropical Medicine and Hygiene 2006;100(5):458-63.

[4] Hiremath SL, Kanta RC, Vasant Kumar CM, et al. Mansonella perstans in ascetic fluid. IJMM 2000;18(3):137-8.

[5] Paniker Jayaram CK. Text book of Medical Parasitology. $6^{\text {th }}$ edn. Filarial worms. Chapter 18. Jaypee Brothers 2011:195.

[6] Centres for disease control and prevention 2016. DPDXlaboratory identification of parasitic diseases of public health concern.

http://www.cdc.gov/dpdx/mansonellosis/tx.html 